\title{
L valve study through dimensionless numbers
}

\section{Estudio de una válvula L a través de números adimensionales}

\author{
Gabriel Cristiano Kuhn ${ }^{1 *} \quad$ Maria Luiza Sperb Indrusiak ${ }^{1} \quad$ Lawrence Shadle $^{2}$ \\ Recibido 11 de enero de 2016, aceptado 29 de abril de 2016 \\ Received: January 11, 2016 Accepted: April 29, 2016
}

\begin{abstract}
$\mathrm{L}$ valve is a right angled, $\mathrm{L}$ shaped pipe applied to transfer solids between two vessels. This device uses gas injection and pipe geometry for controlling the flow of particulate solids. This kind of non-mechanical valve is used in processes such as pneumatic transport lines and circulating fluidized beds. This study aims to develop a new correlation to the solids mass flow rate through dimensional analysis, experimental data and equation fitting. An accurately way to estimate the flow of solids makes easier the design and control of the valve. This study is limited to the influence of L valve geometry, gas injection and particle properties. A test section was built, comprising two valve diameters (acrylic pipes of 34 and $70 \mathrm{~mm}$ ). Glass beads were used as solids (Sauter diameter $0.8 \mathrm{~mm}$, bulk density $1,580 \mathrm{~kg} / \mathrm{m}^{3}$, group D of Geldart classification) and were conveyed by air. Dimensionless numbers were calculated (by Buckingham PI theorem) from the variables of the process, then an experimental program was done. Based on experimental data, $\pi_{1}, \pi_{2}$ and $\pi_{3}$ values were calculated for each test. Mass flux is one variable of $\pi_{1}$. Then a chart was created and a best fit equation was found based on $\pi_{1}, \pi_{2}$ and $\pi_{3}$. Dimensionless numbers were replaced by their equations calculated by Buckingham PI Theorem and solids mass flux can be isolated.
\end{abstract}

Keywords: L valve, dimensional analysis, experimental data, granular flow, Buckingham PI.

\section{RESUMEN}

Válvula L es un tubo en forma de L diseñado para manejar partículas sólidas entre dos reservorios. Este dispositivo utiliza la inyección de gas y su geometría para el control del flujo de sólidos. La aplicación de este tipo de válvula se da en procesos mecánicos que se utiliza para el transporte de partículas, como líneas de transporte neumático y lechos fluidizados circulantes. El objetivo de este trabajo es desarrollar una correlación con la tasa de flujo de masa por medio del análisis de números adimensionales y de datos experimentales. Este estudio considera solamente la influencia de la geometría de la válvula L, la inyección de gas y el cambio de las propiedades de las partículas. El Banco de pruebas ha sido diseñado con dos válvulas L de acrílico (34 y $70 \mathrm{~mm}$ de diámetro). Perlas de vidrio fueron utilizados (Sauter diámetro 0,8 mm, densidad efectiva $1.580 \mathrm{~kg} / \mathrm{m}^{3}$, grupo D de la clasificación Geldart), y accionados por aire comprimido. Aplicando el teorema PI de Buckingham a las variables importantes del proceso, se obtuvieron tres números adimensionales. Después de una batería de pruebas, se calcularon $\pi_{1}, \pi_{2} y \pi_{3}$ para cada ensayo. El flujo de masa es una variable de $\pi_{1}$. Entonces, se elaboró un gráfico y se descubrió la ecuación de la línea de tendencia para cada conjunto de datos trazados, en base a $\pi_{1}, \pi_{2} y \pi_{3}$. Números adimensionales fueron reemplazados por sus respectivas ecuaciones y se aisló el flujo de masa de sólidos.

Palabras clave: Válvula L, datos experimentales, análisis dimensional, flujos granulares, Buckingham PI.

1 PPGEM. Universidade do Vale do Rio dos Sinos. Av. Unisinos, 950. São Leopoldo, RS, Brasil. E-mail: gc_kuhn@yahoo.com.br; mlsperb@unisinos.br

2 National Energy Technology Laboratory. 3610 Collins Ferry Rd. Morgantown, WV, USA.

E-mail: lawrence.shadle@netl.doe.gov

* Autor de correspondencia 


\section{INTRODUCTION}

Solids flow control devices are used in industrial processes where solids must be handled, like in pneumatic transport and fluidized beds [1]. The essential feature is to move solids, without backflow of gas, a difficult task if it is necessary to transfer between reactors at different pressures [2].

These devices are divided into two categories: mechanical valves (rotary, screw, butterfly and slide valves) and non-mechanicals valves ( $\mathrm{L}$ valve, $\mathrm{J}$ valve and $\mathrm{V}$ valve) [1]. Non-mechanical valves have no moving parts in contact with the solid particulate and their action is made by injection of a carrier gas to convey the solids through the bend and the horizontal section of the $\mathrm{L}$ valve [2].

The main difference between a mechanical and a non-mechanical valve is that in a mechanical valve the orifice area is mechanically controlled, while in a non-mechanical one it is pneumatically controlled through aeration [1].

Among all non-mechanical valves, the $\mathrm{L}$ valve is the most popular and it has been used in fluidized bed processes, because it can operate with elevated environment pressures and temperatures [1]. It is a right angled pipe in an $\mathrm{L}$ shape that can connect two vessels between which solids must be transferred [3]. It also has simple design, low cost, effectiveness and minimum maintenance [1].

The dominant controlling factors are the horizontal leg (not the vertical leg) and the terminal velocity of the particles (and not the minimum fluidization velocity of particles) related with the total aeration and the $L$ valve opening [1]. The same author explains that the longer the horizontal leg, the greater the aeration required to initiate the solids flow must be. Conversely, the vertical leg cannot be a limiting factor because its flow is assisted by gravity.

Solids flow rate is affected by elbow radius, number of aeration points and horizontal leg inclination $[1,4]$.

About the elbow radius, a study [5] suggests that less gas is required to transport the same solids rate when the bend is gradual, in other words, solids rate increase as the elbow geometry changes from sharp to gradual. Control sensitivity is improved near the minimum discharge condition when gradual bend is used.

With respect to the elbow inclination, when the horizontal leg is inclined, solids flow rate is increased (any aeration rate) and increase control at low discharge rates [5]. According the same authors, flows at an angle of $16^{\circ}$, below the horizontal section, becomes uncontrollable. For greater values, extensive bypassing of gas along the top of the horizontal tube creates this inability. Geldart and Jones [5] used one injection nozzle, and only resorted to three aeration points when sonic velocity was approached in the injection nozzle and maximum air and solids rates were achieved with three nozzles.

L valves work best with group B particles, do not work well with group A and present many difficulties with group $\mathrm{C}$ particles [3]. If the particle size and pipe diameter are increased, it is necessary to insert a bigger amount of gas to achieve the same solids flow rate [5]. Geldart and Jones [5] plotted solids mass flux $\left(G_{s}\right)$ versus superficial velocity $\left(U_{e x t}\right)$ and the graphics suggested that if solids mass flux is divided by the pipe diameter $(D)$ data might be represented by a single curve. The same authors observed that the minimum superficial aeration velocities $\left(U_{\text {ext }}\right)$ were similar to the minimum fluidization velocities $\left(U_{m f}\right)$ for the sands tested, so with these ideas, the following correlation was created (equation (1)).

$$
\frac{G_{s}}{D}=3354 \cdot \frac{U_{e x t}}{U_{m f}}-2965
$$

This device type has been extensively studied, but it is a complex process and there are still many uncertainties to understand it. The reason to study this new approach to characterize this valve was motivated by the importance of its application. A better way to estimate the flow of solids makes the design and control of the valve easier.

This study aims to contribute to the understanding of the performance of this device by developing a correlation to determine more accurately the solids flow in the discharge valve by combining experimental data and dimensionless numbers. Current literature presents a significant number of studies about this equipment, few of them applying dimensional analysis. That would be the main contribution of this research work. 


\section{METHODOLOGY}

A test stand was constructed for this project, comprising two valve diameters. One kind of solids and some aeration rates were tested for each valve.

This study does not consider the influence of the reactors that an $\mathrm{L}$ valve connect. Therefore, only the $\mathrm{L}$ valve was analyzed. In other words, this approach is limited to the influence of L valve geometry, auxiliary air flow and particle characteristics on the valve performance.

\section{Particulate and Equipment for Testing}

Glass beads were used as solids and were conveyed by air. The glass beads properties are: Sauter diameter $0.8 \mathrm{~mm}$; bulk density $1,580 \mathrm{~kg} /$ $\mathrm{m}^{3}$; particle density $2,490 \mathrm{~kg} / \mathrm{m}^{3}$ and sphericity is 0.872 . Particle characterization was done by Bianchi and Aquino [10].

Two L valves were studied. They were made of two acrylic glass tubes (to observe the flow profile) connected by commercial elbows of PVC. The tubes are $34 \mathrm{~mm}$ and $70 \mathrm{~mm}$ internal diameter. The lower valve is nearly half the diameter of the largest one and the dimensions of both legs were made according to the resources available.

Figure 1 and 2 show the $L$ valve dimensions, including the distance between the top and the horizontal tube center. The aeration point was positioned at one diameter from the centerline of the horizontal tube

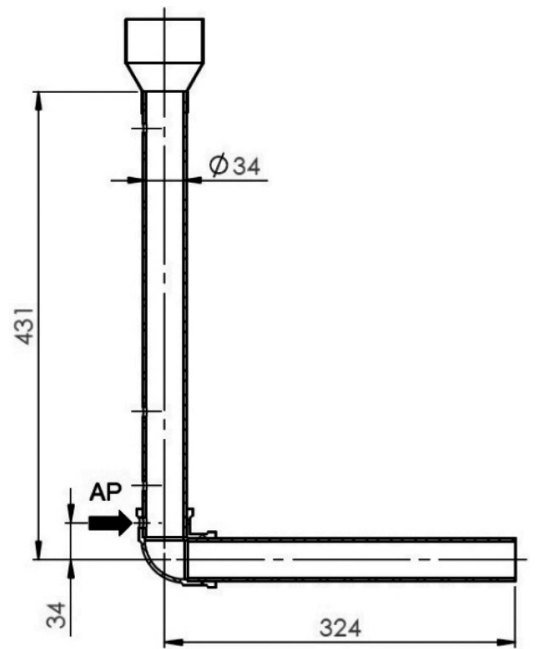

Figure 1. L Valve of $34 \mathrm{~mm}$ diameter. and there are two pressure taps, one is positioned in the middle of the elbow and other $50 \mathrm{~mm}$ from the standpipe top. The air flow rate was measured by a rotameter and the pressure drop across the standpipe by pressure transducers.

A structure was built to support $\mathrm{L}$ valves. Figure 3 shows this device. Between $\mathrm{L}$ valve and the feeder

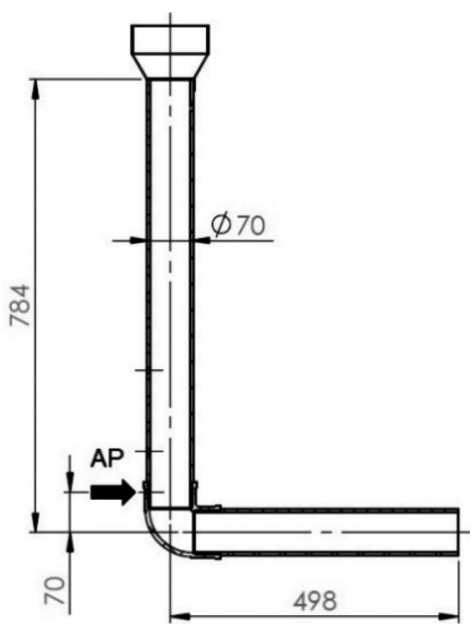

Figure 2. L Valve of $70 \mathrm{~mm}$ diameter.

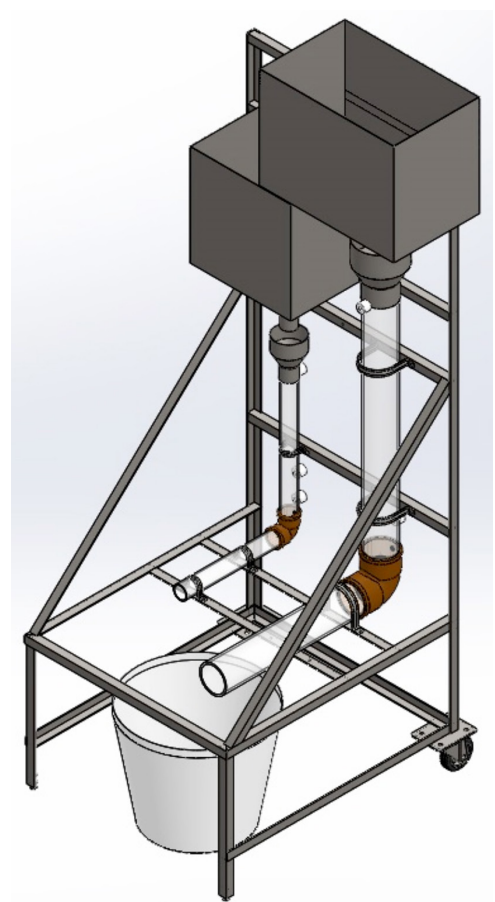

Figure 3. Test section with two L Valves. 
there is a hopper to prevent loss of solids. The vessel right after the discharge prevents solids losses. Downcomer particle level was kept through a device that restricts particles between feeder and hopper. So, depending on the $\mathrm{L}$ valve flow, downcomer particles level can be controlled.

\section{Methodology}

For testing, the procedure is: $\mathrm{L}$ valve and feeder must be filled up with solids. Then aeration is set at a minimum value that solids just begin to trickle from discharge, this condition is kept for some minutes and the first solids flow is measured. Solids flows were determined by collecting solids from discharge, measuring time interval in this process and weighing the solids. Aeration value and downcomer pressure drops are recorded too. The procedure was repeated at least 5 times and a solids flow average is taken for the settled aeration value. The aeration rate is increased by steps until the maximum possible is reached for the selected $\mathrm{L}$ valve. When the maximum possible solids flow is reached, it is not feasible to measure and collect particles.

Dimensional analysis is a method to obtain the dimensionless groups that characterize a physical phenomenon, utilizing the principle that an equation is dimensionally correct when dimensions of all terms are equal [6]. Buckingham Pi $(\pi)$ theorem is a procedure for deducing dimensionless groups for a given engineering problem and it allows developing nondimensional parameters easily [7]. However, this knowledge must be supplemented by experimental data to determine the functional relationship between the groups of variables [6].

The variables of the process were analyzed and the following were selected: $D$ - $L$ valve diameter; $G_{s}$ - mass flux of solids through the $\mathrm{L}$ valve; $\Delta_{D C}{ }^{-}$ pressure drop between aeration point and the top of downcomer; $U_{m f}$ - minimum fluidization velocity; $L_{h}$ - horizontal length of the L valve; $Q_{e x t}$ - external aeration rate.

The Buckingham PI was calculated with the variables mentioned before, as shown in equation (2). Therefore, the procedure used to find an equation, based in experimental data, follow the same idea like proposed by Stoecker [9] to develop a function of two variables, in the present case using an exponential equation.

$$
\pi_{1}=\frac{Q_{e x t} \cdot G_{s}}{\Delta_{D C} \cdot D^{2}}, \pi_{2}=\frac{D^{2} \cdot U_{m f}}{Q_{e x t}}, \pi_{3}=\frac{L_{h}}{D}
$$

In the study of Santoyo, Guatemala, Orozco and Arriola [8], three dimensionless numbers were calculated and these were the variables to find the solids flux for an $\mathrm{S}$ valve through their data and Davis method ( $\mathrm{S}$ valve is a device to convey granular solids by a gas rate in a controlled pressure) [8].

\section{RESULTS}

Figure 4 shows a chart with the tests results. The profile of these curves look like the data from Geldart and Jones [5], however their values are different because they used sand and the particles diameter were smaller.

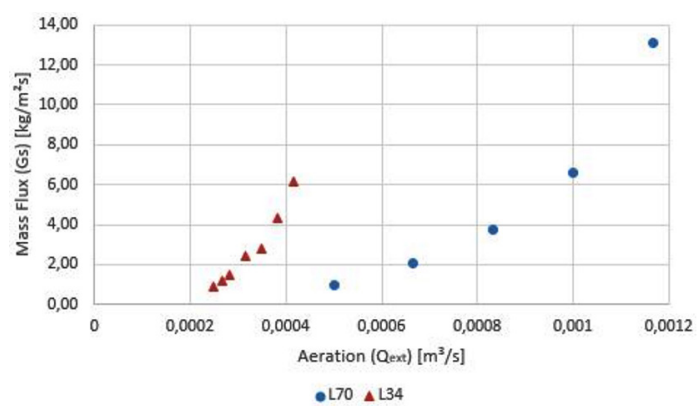

Figure 4. Data from tests, Mass flux $\left(G_{s}\right)$ versus aeration rate $\left(Q_{e x t}\right)$.

The dimensionless numbers were calculated according to equation (2), the results are in Table 1. It is important to note that $\pi_{3}$ does not change when the aeration rate is changed because this dimensionless numbers are a division of two constants.

\section{Analyses}

Figure 5 shows $\pi_{1}$ versus $\pi_{2}$. Equation (3) fits the data points.

$$
y=a \cdot x^{b}
$$

Equations (4) and (5) show best fit equations for $34 \mathrm{~mm}$ and $70 \mathrm{~mm}$, respectively.

$$
\begin{aligned}
& \pi_{1(34 \mathrm{~mm})}=0.0068 \pi_{2}^{-2.96} \\
& \pi_{1(70 \mathrm{~mm})}=0.0303 \pi_{2}^{-3.35}
\end{aligned}
$$


Table 1. Dimensionless numbers calculated based on experimental data.

\begin{tabular}{|c|c|c|c|}
\hline \multicolumn{4}{|c|}{ L Valve $34 \mathrm{~mm}$} \\
\hline Test & $\pi_{1}$ & $\pi_{2}$ & $\pi_{3}$ \\
\hline 1 & 0.0004375 & 2.529328 & 9.529412 \\
\hline 2 & 0.0005391 & 2.371245 & 9.529412 \\
\hline 3 & 0.0006075 & 2.231760 & 9.529412 \\
\hline 4 & 0.0009018 & 1.996838 & 9.529412 \\
\hline 5 & 0.0010834 & 1.806663 & 9.529412 \\
\hline 6 & 0.0015309 & 1.649562 & 9.529412 \\
\hline 7 & 0.0020530 & 1.517597 & 9.529412 \\
\hline \multicolumn{4}{|c|}{ L Valve $70 \mathrm{~mm}$} \\
\hline Test & $\pi_{1}$ & $\pi_{2}$ & $\pi_{3}$ \\
\hline 1 & 0.0001323 & 5.360600 & 7.114286 \\
\hline 2 & 0.0002818 & 4.020450 & 7.114286 \\
\hline 3 & 0.0005233 & 3.216360 & 7.114286 \\
\hline 4 & 0.0008332 & 2.680300 & 7.114286 \\
\hline 5 & 0.0015551 & 2.297400 & 7.114286 \\
\hline
\end{tabular}

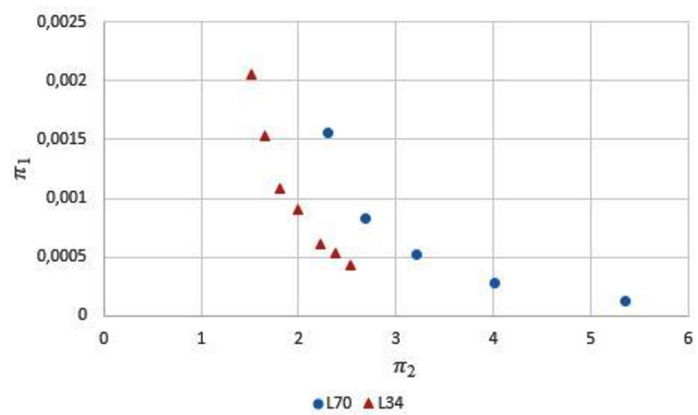

Figure 5. Dimensionless numbers $\pi_{1}$ versus $\pi_{2}$.

With coefficients $a$ and $b$ from Figure 5 (coefficients a: 0.0068 and 0.0303 . Coefficients b: -2.96 and -3.35 . All of them are shown in equations (4) and (5)), plotted against $\pi_{3}$, Figure 6 is found. Then the equation of the two curves can be calculated.

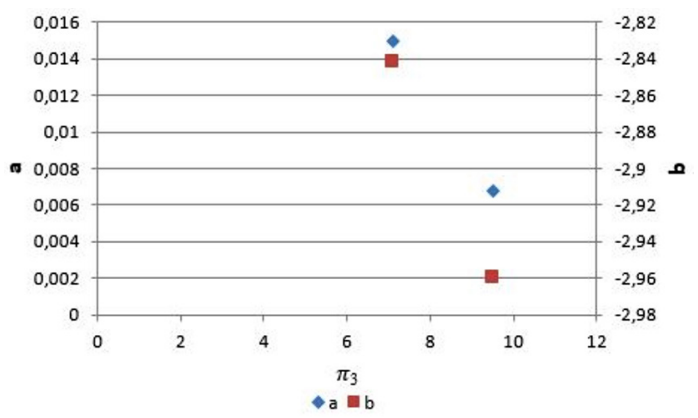

Figure 6. Coefficients $a$ and $b$ vs. $\pi_{3}$.
Equation (6) expresses $\pi_{1}$ in function of $\pi_{2}$ and $\pi_{3}$. In other words, this equation is similar to equation (3), but variables were substituted by $\pi_{1}, \pi_{2}$ and $\pi_{3}$ and coefficients from Figures 5 and 6.

$$
\pi_{1}=\left(-0.0034 \pi_{3}+0.0392\right) \pi_{2}^{\left(-0.0489 \pi_{3}-2.4944\right)}
$$

If dimensionless numbers are substituted in equation (6), mass flux, Gs, can be isolated and a correlation to calculate Gs is found, as equation (7) shows.

$$
\begin{gathered}
G_{s}=\left[\left(-0.0034 \frac{L h}{D}+0.0392\right)\left(\frac{D^{2} U_{m f}}{Q_{\text {ext }}}\right)^{Z}\right] w \\
\text { Where }: z=\left(-0.0489 \cdot \frac{L h}{D}-2.4944\right) ; w=\frac{\Delta_{D C} D^{2}}{Q_{e x t}}
\end{gathered}
$$

Table 2 compares values of $\pi_{1}$ calculated with equation (6) and experimental data. The table shows the percentage of the difference between the experimental and calculated values of $\pi_{1}$. The larger difference was $9 \%$, being considered acceptable to validate equation (6) due to the complexity of the process.

\section{CONCLUSIONS}

This study on L valve found a correlation through dimensional analyses to calculate mass flux, limited by one particle diameter and two different $L$ valves. Two different pipe sizes and one kind of particulate in two diameters were used. The purpose is to predict the mass flux from the characteristic parameters of an $\mathrm{L}$ valve, as an auxiliary tool to the design of such devices.

The next step will be to review dimensionless numbers because particle diameter may be an important parameter and it was not considered. Bigger aeration rate (for both $\mathrm{L}$ valves) can be achieved but some new apparatus and experimental technique should be developed.

Correlation proposed by Geldart and Jones [5] (equation (1)) did not work with experimental data obtained in this study. Probably the main reason for that is the size and material of the particles (they used a smaller diameter, and the solids utilized was sand). Some tests with sand will be done to confirm equation (1) with this data and to validate this hypothesis. 
Table 2. Dimensionless numbers calculated based on equation (6) and experimental data.

\begin{tabular}{|c|c|c|c|}
\hline \multicolumn{4}{|c|}{ L Valve $34 \mathrm{~mm}$} \\
\hline Test & $\begin{array}{c}\pi_{1} \\
\text { (Calculated) }\end{array}$ & $\begin{array}{c}\pi_{1} \\
\text { (Data)** }\end{array}$ & $\begin{array}{c}\text { Difference } \\
{[\%]}\end{array}$ \\
\hline 1 & 0.00043597 & 0.00043755 & 0.4 \\
\hline 2 & 0.00052776 & 0.00053911 & 2.1 \\
\hline 3 & 0.00063151 & 0.00060755 & 3.9 \\
\hline 4 & 0.00087776 & 0.00090180 & 2.7 \\
\hline 5 & 0.00118046 & 0.00108339 & 9.0 \\
\hline 6 & 0.00154530 & 0.00153089 & 0.9 \\
\hline 7 & 0.00197795 & 0.00205300 & 3.7 \\
\hline \multicolumn{4}{|c|}{ L Valve 70 mm } \\
\hline Test & $\begin{array}{r}\pi_{1} \\
\text { (Calculated) }\end{array}$ & $\begin{array}{r}\pi_{1} \\
(\text { Data) } * *\end{array}$ & $\begin{array}{c}\text { Difference } \\
{[\%]}\end{array}$ \\
\hline 1 & 0.00012700 & 0.00013231 & 4.0 \\
\hline 2 & 0.00028767 & 0.00028180 & 2.1 \\
\hline 3 & 0.00054243 & 0.00052332 & 3.7 \\
\hline 4 & 0.00091075 & 0.00083315 & 9.3 \\
\hline 5 & 0.00141151 & 0.00155507 & 9.2 \\
\hline
\end{tabular}

* Calculated by equation (6)

** Calculated based on experimental data.

\section{ACKNOWLEDGEMENTS}

Author Kuhn, G. C. acknowledge FAPERGS for the Grant.

\section{REFERENCES}

[1] Y. Wen-Ching and T.M. Knowlton. "L-valve equations". Powder Technology. Vol. 77, pp. 49-54. October, 1993. DOI: 10.1016/0032-5910(93)85006-U.
[2] K. Smolders and J. Baeyens. "The operation of L-valves to control standpipeflow". Advanced Powder Technol. Vol. 6, pp. 163176. February, 1995. DOI: 10.1016/ S0921-8831(08)60525-7.

[3] B. Prabir. "Combustion and Gasification in Fluidized Beds". Boca Raton: Taylor \& Francis. 2006. ISBN: 0849333962.

[4] M.A. Daous and A.A. Al-Zahrani. "Modeling solids and gas flow through an L-valve. Powder Technology. Vol. 99, pp. 86-89. April, 1998. DOI: 10.1016/S0032-5910(98)00062-X.

[5] D. Geldart and P. Jones. "The behavior of L-valves with granular powders". Powder Technology. Vol. 67, pp. 163-174. February, 1991. DOI: 10.1016/0032-5910(91)80153-A.

[6] Y. Nakayama and R. Boucher. "Introduction to Fluid Mechanics". Tokyo. ButterworthHeinemann. 2000. ISBN: 0340676493.

[7] R.W. Fox. P.J. Pritchard e A.T. McDonald. "Introdução à Mecânica dos Fluidos". 7ed. Rio de Janeiro, Brazil. LTC. 2010. ISBN: 9788521617570.

[8] F. Santoyo, G. Guatemala, I. Orozco y E. Arriola. "La Válvula-S: Modelando del Flujo de Sólidos Granulares Utilizando Números Adimensionales". Revista Mexicana de Ingeniería Química. Vol. 9, pp. 179-188. March, 2010. ISSN: 1665-2738.

[9] W.F. Stoecker. "Design of Thermal Systems". [S.I.]: McGraw-Hill. 1989. ISBN: 007 0616205.

[10] F.M. Bianchi e T.F. Aquino. "Bancada de leito fluidizado circulante a frio: experimentos e análise de dados". Course Conclusion Article. Faculty SATC. Criciúma, Brazil. 2014. 